\title{
Immune-mediated inflammation directly impairs pulmonary function, contributing to the pathogenesis of Pneumocystis carinii pneumonia
}

\author{
Terry W. Wright, ${ }^{1}$ Francis Gigliotti, ${ }^{1,2}$ Jacob N. Finkelstein,${ }^{1}$ John T. McBride, ${ }^{1}$ \\ Chun Li An, ${ }^{3}$ and Allen G. Harmsen ${ }^{3}$ \\ ${ }^{1}$ Department of Pediatrics, and
${ }^{2}$ Department of Microbiology and Immunology, University of Rochester School of Medicine, Rochester, New York 14642, USA
${ }^{3}$ Trudeau Institute Inc., Saranac Lake, New York 12983, USA
}

Address correspondence to: Terry W. Wright, University of Rochester Medical Center, 601 Elmwood Avenue, Box 690, Rochester, New York 14642, USA. Phone: (716) 275-4246; Fax: (716) 273-1104; E-mail: Terry_Wright@urmc.rochester.edu.

Received for publication March 2, 1999, and accepted in revised form August 30, 1999.

The clinical severity of Pneumocystis carinii pneumonia (PCP) correlates closely with the appearance of pulmonary markers of inflammation. Therefore, a model system was developed whereby physiological studies could be performed on live mice to determine the extent to which pulmonary inflammation contributes to respiratory impairment during PCP. P. carinii-infected severe combined immunodeficient mice displayed little evidence of pulmonary inflammation and exhibited normal oxygenation and dynamic lung compliance. When comparably infected littermates were immunologically reconstituted, however, an intense immune-mediated inflammatory response was observed that resulted in significant decreases in both lung compliance and oxygenation. As the pneumonia resolved, pulmonary function returned toward normal. To begin to define the cell populations contributing to inflammation-associated respiratory impairment during PCP, similar studies were performed in $\mathrm{CD}^{+} \mathrm{T}$ cell-depleted mice. Mice depleted of both $\mathrm{CD}^{+}$and $\mathrm{CD}^{+}$cells developed infection, but they demonstrated neither abnormal lung compliance nor increased respiratory rate and displayed no markers of lung injury. In contrast, mice depleted of only $\mathrm{CD} 4^{+} \mathrm{T}$ cells exhibited severe pulmonary inflammation and injury, decreased oxygenation and lung compliance, and increased respirations. Respiratory compromise was associated with the presence of activated CD8 ${ }^{+}$cells and neutrophils in broncho-alveolar lavage fluid. These observations provide direct experimental evidence that the host's response to $P$. carinii directly impairs pulmonary function and contributes to the pathogenesis of PCP. Furthermore, $\mathrm{CD}^{+} \mathrm{T}$ cells likely contribute to the respiratory compromise observed during PCP.

J. Clin. Invest. 104:1307-1317 (1999).

\section{Introduction}

Pneumocystis carinii produces a life-threatening pneumonia in immunocompromised patients, especially those with AIDS. The clinical syndrome of $P$. carinii pneumonia (PCP) has been well described in terms of presentation, diagnostic and therapeutic interventions, as well as morbidity and mortality. Whereas the hallmark of PCP is profound hypoxia, the type and extent of lung injury produced by $P$. carinii has never been defined or characterized. Defining the interplay of $P$. carinii with host inflammatory cells, cytokines, and toxic metabolites, and the involvement of both cellular and humoral immunity in the pathogenesis of PCP, has recently been put forth as an important area of investigation to develop new therapies for this disorder (1).

The morbidity and mortality from PCP remain high. In fact, among adult patients who do not have AIDS, the mortality remains as high as $50 \%$ in some series and has changed little over the past 2 decades (2). In contrast, mortality among AIDS patients has dropped to $10-15 \%(3,4)$. Part of the drop in mortality is undoubtedly due to the more aggressive management of AIDS patients. Because both AIDS and non-AIDS patients have access to essentially the same care, however, excess mortality in non-AIDS patients remains unexplained. Our working hypothesis is that a major contributor to the morbidity and mortality from PCP is the host inflammatory response to infection by $P$. carinii. To date, there are no published data, either from animal models or clinical studies, that provide direct evidence that the host inflammatory response contributes significantly to the pathophysiology of PCP. There are, however, many clinical observations that suggest that a patient's ability to mount an inflammatory response correlates directly with the severity of the clinical manifestation of PCP. For example, recent studies have found that increased broncho-alveolar lavage fluid (BALF) IL-8 and neutrophil concentrations, but not organism number, correlate with poorer oxygenation and decreased survival rates in PCP patients $(5,6)$. AIDS patients often have higher organism burdens, yet demonstrate less pulmonary inflam- 

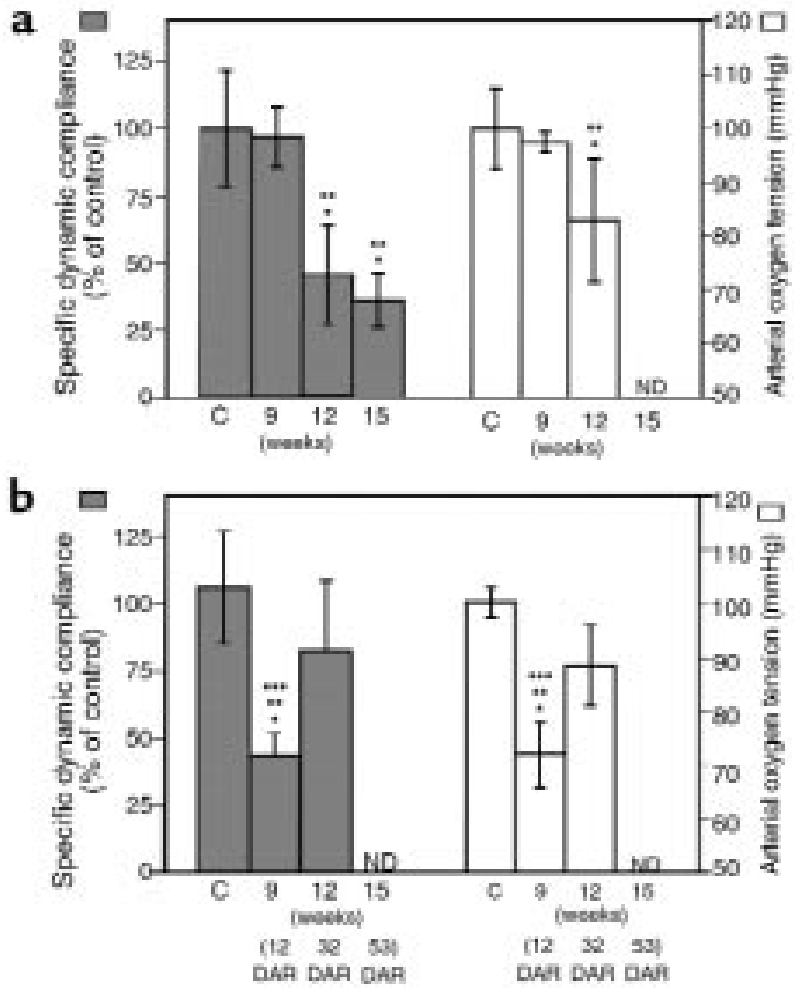

\section{Figure 1}

Impaired pulmonary function during PCP in SCID mice. For comparison of nonreconstituted and reconstituted SCID mice, time points are expressed in weeks after exposure to $P$. carinii. (a) Progressive decline in specific lung compliance and $\mathrm{PaO}_{2}$ in nonreconstituted $P$. carinii-infected SCID mice. (b) Respiratory impairment and recovery after immune reconstitution of $P$. carinii-infected SCID mice. ND, not determined. C, $P$. carinii-free control. ${ }^{*} P<0.05$ vs. $P$. carinii-free controls. ${ }^{*} P<0.05$ vs. $P$. carinii-infected SCID mice at 9 weeks after exposure. ${ }^{* *} P<0.05$ vs. reconstituted $P$. carinii-infected SCID mice at 32 DAR.

mation, including fewer BALF neutrophils, than nonAIDS patients (6). Among cancer patients, the observation has been made that PCP may be more likely to manifest itself when the dosage of corticosteroids is being reduced (2). The improved outcome that has been noted in patients with moderately severe PCP who receive corticosteroids has been attributed to the anti-inflammatory effects of the steroids, although proof of this mechanism of action in PCP is lacking (7). All of these observations are consistent with the hypothesis that the host inflammatory response to $P$. carinii can have a deleterious clinical effect.

The purpose of the experiments described in this report was to determine whether an animal model of PCP could provide objective evidence of the relationship between the inflammatory response and pulmonary injury as a result of PCP. Furthermore, we wanted to develop a model system that would allow us to manipulate the inflammatory response in order to define more precisely the mechanism of pulmonary dysfunction observed during PCP. The severe combined immunodeficient (SCID) mouse model of PCP $(8,9)$ provides a defined system whereby the onset, course, and outcome of $\mathrm{PCP}$ can be controlled by various experimental manipulations. Using this system, we have shown previously that the proinflammatory cytokine response to $P$. carinii in the absence of an immune response, i.e., in nonreconstituted SCID mice, differed markedly from that observed in the presence of functional immune cells, i.e., after reconstitution $(10,11)$. By determining the effect of the immune response to PCP on dynamic lung compliance and arterial oxygen saturation, we hoped to provide physiologic evidence for immune-mediated lung injury as the mechanism of respiratory compromise observed during PCP. Furthermore, by using the CD4-depleted mouse model of PCP $(12,13)$, we wanted to determine which type(s) of immune cells were major contributors to PCP-associated respiratory impairment in hosts suffering from chronic $\mathrm{CD}^{+} \mathrm{T}$-cell deficiencies. We hope that the insights gained from such studies will be useful in developing adjunctive therapy for PCP in humans.

\section{Methods}

Mouse models of PCP. CB.17 scid/scid mice were obtained from the Trudeau Institute Animal Breeding Facility (Saranac Lake, New York, USA). The mice are maintained in microisolator cages and fed sterilized food and water. Beginning at 3 weeks of age, the $P$. carinii-free SCID mice were cohoused with $P$. carinii-infected SCID mice to induce PCP in the experimental animals. Five to 7 weeks after commencing cohousing (after exposure), when SCID mice are known to have developed PCP, the mice were immunologically reconstituted with $5 \times 10^{7}$ spleen cells from normal congenic CB.17 mice. Following reconstitution, organisms were cleared by about 3 weeks (14). At various times, as indicated, measurements of arterial oxygenation and dynamic lung compliance were done. The lungs of some mice were removed after dynamic compliance measurements were taken. These lungs were homogenized and aliquots were stained with Gomori's methenamine-silver to confirm and quantify the $P$. carinii burden.

Female C57BL/ 6 mice, 4 weeks of age, were obtained from Trudeau Institute Animal Breeding Facility. Three days after arrival, mice were assigned to receive antiCD4 mAb (clone GK 1.5, ATCC), both anti-CD4 and anti-CD8 mAbs (clone TIB210, ATCC), an equal amount of isotype-matched control mAb (HRP), or assigned to a no-antibody control group as described previously (12). Mice treated with mAb received intraperitoneal injections of $0.25 \mathrm{mg}$ of $\mathrm{mAb}$ in $0.5 \mathrm{~mL}$ HBSS 2 times per week. Injections of mAbs were continued for the duration of the experiments.

P. carinii inoculation. Lungs from CB.17 SCID mice maintained in a $P$. carinii-infected colony were used as a source of $P$. carinii (12). Recipient mice were anesthetized with halothane gas and given intratracheal inoculations of $100 \mu \mathrm{L}$ of lung homogenates containing $10^{8} \mathrm{P}$. carinii nuclei/mL with a blunted 20 -gauge needle inserted into the trachea through the oral pharynx as described previously (15). 


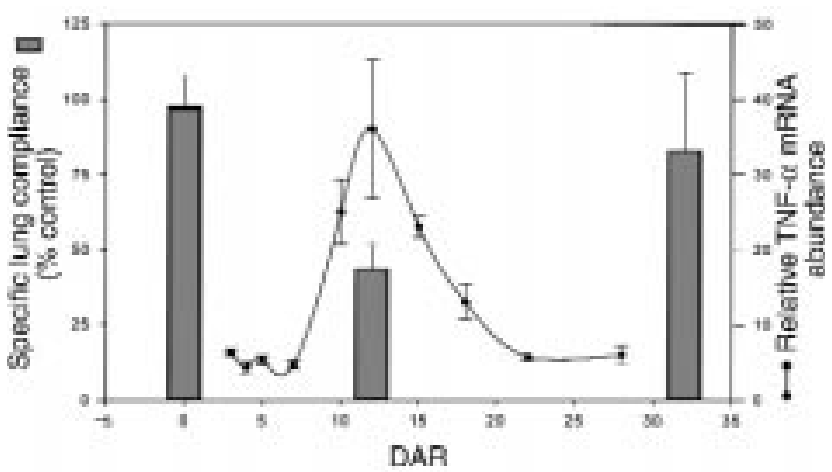

Figure 2

Temporal relationship of pulmonary inflammation and specific dynamic lung compliance after immune reconstitution of $P$. carinii-infected $\mathrm{SCID}$ mice. Dynamic lung compliance and pulmonary TNF- $\alpha$ mRNA abundance were measured at various times after reconstitution. The time course ofTNF- $\alpha$ mRNA abundance has been reported previously (10) and serves as a reliable marker of pulmonary inflammation in this model. Pulmonary inflammation is minimal and lung compliance is normal in infected mice at 0 DAR. However, during the peak inflammatory phase after reconstitution (12 DAR), lung compliance is dramatically decreased. Finally, by 32 DAR the infection has been cleared, pulmonary inflammation is resolving, and lung compliance measurements approach normal.

Arterial blood gas determination. Mice were gently heated in their cages with a heat lamp to increase peripheral blood flow. The mice were then restrained by hand, and the ventral artery of the tail was nicked by carefully plunging a small scalpel blade diagonally into the artery. Care was taken not to cut the skin and surrounding tissue any more than necessary to obtain arterial blood and thus limit venous blood contamination. Heparin was swabbed onto the skin before it was cut to minimize clotting. About $100 \mu \mathrm{L}$ of blood was collected in a heparinized capillary tube and immediately placed on ice. Blood in the capillary tube was mixed by placing a small metal fragment into the tube and then passing a magnet along the length of the tube several times. The samples were analyzed on a clinical blood gas machine within 60 minutes of drawing. Bleeding was controlled by wrapping the puncture site with commercial grade duct tape.

Physiologic assessment of pulmonary compliance in live, ventilated mice. Pulmonary compliance was measured in live mice using a method described previously, with modifications (16). Mice were anesthetized with 0.13 mg sodium pentobarbital per gram of body weight administered intraperitoneally. Mice were then surgically cannulated through the trachea with an 18-gauge cannula inserted $3 \mathrm{~mm}$ into an anterior nick in the exposed trachea and imme-

Table 1 at 11 weeks after exposure. diately placed on a Harvard rodent ventilator (Harvard Apparatus, South Natick, Massachusetts, USA) at a respiratory rate of 150 strokes per minute. To ensure that the mice tolerated the procedure, they were examined for spontaneous respirations before proceeding further. The thorax was opened to equalize airway and transpulmonary pressure. The animal was placed in a pressure plethysmograph and ventilated at $2.5 \mathrm{~Hz}$ with a tidal volume of .01 milliliter per gram of body weight. Signals for airway pressure and volume were passed through an analogue-to-digital converter and used to calculate pulmonary compliance using the method of Amdur and Mead (17). Compliance was normalized for either body weight or length, as indicated.

Respiratory rate determination. Respiratory rates were measured in live mice using plethysmograph equipment (Harvard Apparatus).

Determination of albumin concentration in BALF. Aliquots of cell-free lung lavage fluids were tested for albumin content by a colorimetric method (Sigma Diagnostics, St. Louis, Missouri, USA) as described previously (18). Determination of lactate dehydrogenase activity in sera. Aliquots of sera were assayed for lactate dehydrogenase (LDH) activity by a quantitative, colorimetric method (procedure \# 500; Sigma Diagnostics).The results were expressed in the terms of Bergar-Broida units per milliliter of serum $(\mathrm{BBU} / \mathrm{mL})$.

Cellular composition of BALF. After dynamic compliance measurements were taken on experimental mice, the lungs were lavaged as described previously (15). Five 1$\mathrm{mL}$ volumes of $1 \mathrm{X}$ HBSS were washed through the lungs via the tracheal cannula. The lavage cells were collected by centrifugation at $200 \mathrm{~g}$ for 5 minutes. The cells were then washed with fresh HBSS, centrifuged onto glass slides, and stained with Diff-Quick (Dade AG, Dudingen, Switzerland) for differential counting.

Enumeration of $P$. carinii. The intensity of $P$. carinii infection in mouse lungs was determined by enumeration of $P$. carinii nuclei as described previously (12). Briefly, right lobes of lung were excised and pushed through stainless-steel mesh screens in HBSS. Aliquots of the lung homogenates were spun onto glass slides with a cytocentrifuge, and smears were stained with Diff-Quik. The number of $P$. carinii nuclei per 10 (for heavy infections) to 50 oil immersion fields were count-

$\mathrm{PaO}_{2}$ in nonreconstituted and immunologically reconstituted SCID mice

\begin{tabular}{lcccccc}
\hline $\begin{array}{l}\text { Experimental } \\
\text { group }\end{array}$ & $n$ & $\begin{array}{c}\text { Weeks after } \\
\text { exposure }\end{array}$ & $\begin{array}{c}\text { Immune } \\
\text { reconstitution }\end{array}$ & DAR & $\begin{array}{c}\mathrm{PaO}_{2} \\
(\mathrm{mmHg})\end{array}$ & $\begin{array}{c}\text { Body weight } \\
(\mathrm{g})\end{array}$ \\
$\begin{array}{l}\text { P. carinii-free } \\
\text {. carinii-infected }\end{array}$ & 5 & 0 & $\mathrm{No}$ & 0 & $97.0 \pm 3.3$ & $20.0 \pm 1.0$ \\
$\begin{array}{l}\text { P. carinii-infected } \\
\text { P. carinii-infected }\end{array}$ & 6 & 11 & $\mathrm{No}$ & 0 & $88.0 \pm 7.4$ & $19.4 \pm 1.6$ \\
& 5 & 11 & Yes & 8 & $82.0 \pm 6.9^{\mathrm{A}}$ & $16.5 \pm 0.9^{\mathrm{A}, \mathrm{B}}$ \\
\end{tabular}

Arterial oxygenation and body weight measurements were taken in nonreconstituted and reconstituted $P$. carinii-infected SCID mice. P. carinii-free SCID mice were used as normal controls. Values are mean $\pm 1 \mathrm{SD}$ and $n$ is the number of mice in each group. ${ }^{A} P<0.05$ vs. $P$. carinii-free $S C I D$ mice. ${ }^{B} P<0.05$ vs. nonreconstituted $P$. carinii-infected SCID mice 
Table 2

Dynamic lung compliance in nonreconstituted and immunologically reconstituted SCID mice

$\begin{array}{lccccc}\text { Experimental group } & n & \begin{array}{c}\text { Weeks after } \\ \text { exposure }\end{array} & \begin{array}{c}\text { Immune } \\ \text { reconstitution }\end{array} & \text { DAR } & \begin{array}{c}\text { Specific } \\ \text { compliance } \\ \text { (\% control) }\end{array} \\ \text { P. carinii-free } & 4 & 0 & \text { No } & 0 & 100.0 \pm 16.5 \\ P . \text { carinii-infected } & 5 & 9 & \text { No } & 0 & 100.0 \pm 16.1 \\ P . \text { carinii-infected } & 4 & 9 & \text { Yes } & 13 & 67.0 \pm 16.8^{\mathrm{A}, \mathrm{B}} \\ P . \text { carinii-infected } & 4 & 12 & \text { No } & 0 & 64.0 \pm 15.9^{\mathrm{A}, \mathrm{B}}\end{array}$

Specific dynamic lung compliance measurements were taken in nonreconstituted and reconstituted $P$. carinii-infected SCID mice. $P$. carinii-free SCID mice were used as controls to establish a normal range for lung compliance. Lung compliance values were corrected for body weight and expressed as percentages of $P$. carinii-free controls. Values are mean $\pm 1 \mathrm{SD}$ and $n$ is the number of mice in each group. ${ }^{A} P<0.05$ vs. $P$. carinii-free SCID mice. ${ }^{B} P<0.05$ vs. nonreconstituted $P$. carinii-infected SCID mice at 9 weeks after exposure.

ed, and the total $P$. carinii nuclei per lung were calculated. The limit of detection by this method was log 4.20 for whole lung homogenates. In addition, the numbers of $P$. carinii trophozoites and cysts in lung homogenates and BALF were counted separately, and the ratio of trophozoites to cysts was calculated.

Statistical analyses. For each experiment, a 1-way ANOVA was performed using the SigmaStat software package (Jandel Scientific, San Rafael, California, USA). The Student-Newmann-Keuls method was used for all pairwise multiple comparisons of experimental groups.

\section{Results}

Pulmonary inflammation contributes to impaired oxygenation in P. carinii-infected SCID mice following immune reconstitution. SCID mice develop active $P$. carinii infections without mounting an effective pulmonary inflammatory response against the organism. If these mice are immunologically reconstituted, however, an intense $P$. carinii-driven inflammatory response peaking between 10 and 15 days after reconstitution (DAR) is observed (9-11). To determine whether immune-mediated inflammation contributes to decreased oxygenation during PCP, arterial oxygen tension $\left(\mathrm{PaO}_{2}\right)$ was measured in reconstituted and nonreconstituted $P$. carinii-infected SCID mice. $P$. carinii-free SCID mice were used as controls to establish a normal range for $\mathrm{PaO}_{2}$ in mice. The mean $\mathrm{PaO}_{2}$ values of the $P$. carinii-free SCID mice examined were $97 \pm 3.3 \mathrm{mmHg}$ (Table 1). The effect of inflammation on oxygenation was studied in 16 P. carinii-infected SCID mice. At 10 weeks after exposure, 11 of the mice were reconstituted and 5 were not. Eleven days later, the nonreconstituted $P$. carinii-infected SCID mice did not exhibit a significant decrease in $\mathrm{PaO}_{2}$ as compared with uninfected controls ( $88 \pm 7.4 \mathrm{mmHg}$ ). The $\mathrm{PaO}_{2}$ values, however, were significantly decreased to $82 \pm 6.9 \mathrm{mmHg}$ in the reconstituted mice at $8 \mathrm{DAR}(P<0.05$, as compared with $P$. carinii-free control SCID mice), and further decreased to $71 \pm 7.5 \mathrm{mmHg}$ at $11 \mathrm{DAR}$ during the peak inflammatory phase following reconstitution $(P<0.05$, as compared with $P$. carinii-free and nonreconstituted $P$. carinii-infected SCID mice). In addition, the recon- stituted animals exhibited labored breathing, lethargy, and significant weight loss. By 11 DAR the reconstituted mice had lost an average of $19 \pm 10 \%$ of their body weight as compared with nonreconstituted, infected mice $(P<0.05$; Table 1). These experiments demonstrated that host inflammation directly contributed to poorer oxygenation and poorer overall health in reconstituted $P$. carinii-infected SCID mice.

Pulmonary inflammation contributes to impaired dynamic lung compliance in $P$. carinii-infected SCID mice. Pulmonary inflammation following immune reconstitution contributed to poorer oxygenation during PCP in SCID mice (Table 1). To determine whether the $P$. carinii-driven inflammatory response contributes to poorer oxygenation through effects on lung function, physiological measurements of pulmonary function were taken on reconstituted and nonreconstituted $P$. carinii-infected SCID mice (Table 2). P. carinii-free SCID mice were used as controls to establish a normal range for compliance measurements. The mean specific lung compliance of the $P$. carinii-free SCID mice examined was $1.10 \mathrm{~mL} / \mathrm{cmH}_{2} \mathrm{O}$ per kilogram. For each experiment the mean compliance of the $P$. carinii-free group was assigned a value of $100 \%$ compliance, and the compliance of each experimental group was expressed as percent of control. At 7 weeks after exposure, half of the P. carinii-infected SCID littermates were reconstituted and half were not. Thirteen days later, during the peak inflammatory stage following reconstitution, specific lung compliance measurements were taken on both groups. The pulmonary compliance of nonreconstituted $P$.

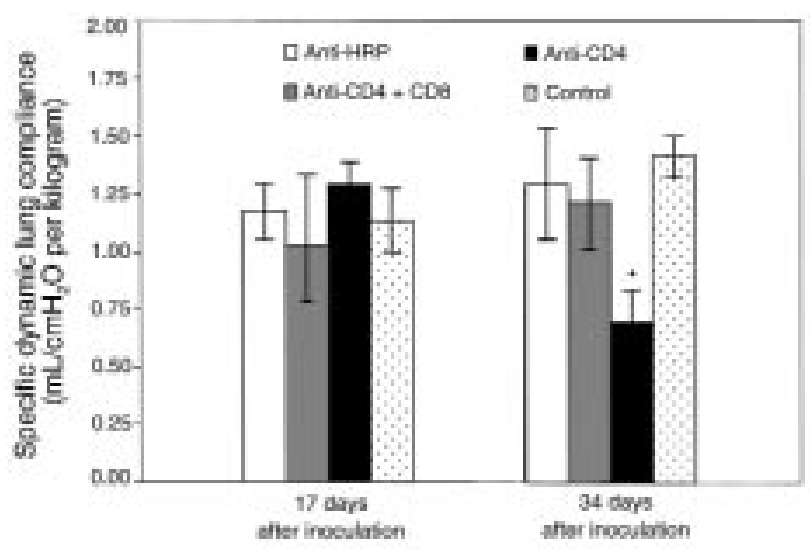

Figure 3

Effect of CD8 ${ }^{+} \mathrm{T}$ cells on dynamic lung compliance during PCP in mice. Specific dynamic lung compliance measurements were taken on CD4-depleted, CD4/CD8-depleted, and anti-HRP-treated mice inoculated with $P$. carinii 17 or 34 days previously. Controls were uninfected C57BL/ 6 mice. Values are mean $\pm 1 \mathrm{SD}(n=5) .{ }^{*} P<0.05$ vs. CD4/CD8-depleted, anti-HRP-treated, and uninfected mice at 17 and 34 days after inoculation. 


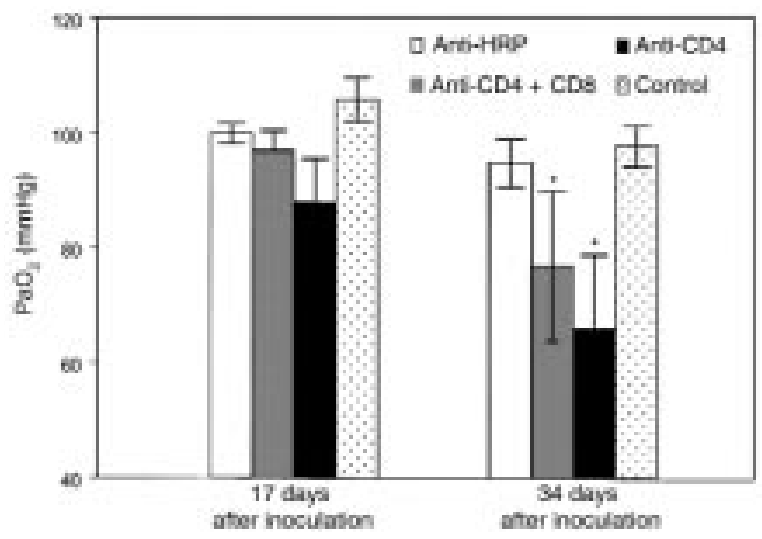

Figure 4

Effect of $C D 8^{+} T$ cells on arterial oxygenation during PCP in mice. $\mathrm{PaO}_{2}$ was measured in CD4-depleted, CD4/CD8-depleted, and anti-HRP-treated mice inoculated with P. carinii 17 or 34 days previously. Controls were uninfected $\mathrm{C} 57 \mathrm{BL} / 6$ mice. Values are mean \pm $1 \mathrm{SD}(n=5) .{ }^{*} P<0.05$ vs. anti-HRP-treated and uninfected mice at 34 days after inoculation.

carinii-infected SCID mice remained normal (100 \pm $16 \%)$ despite active infection. The lung compliance of the reconstituted mice, however, had declined significantly to $67 \pm 17 \%$ of controls $(P<0.05$, as compared with $P$. carinii-free and nonreconstituted $P$. carinii-infected SCID mice). Furthermore, the reconstituted mice exhibited labored breathing and lethargy, whereas the nonreconstituted animals appeared healthy. Thus, the immunological response to P. carinii directly contributed to impaired pulmonary function before any adverse effects were noted from $P$. carinii itself. It is important to note that with more advanced PCP (12 weeks after exposure) the nonreconstituted, $P$. carinii-infected SCID mice exhibited significantly decreased lung compliance even in the absence of immune reconstitution (Table 2).
Time course of pulmonary dysfunction in P. carinii-infected SCID mice. A third series of experiments was performed to establish a time course of pulmonary dysfunction in nonreconstituted SCID mice and to characterize further the inflammation-associated respiratory impairment following reconstitution. In the absence of lymphocytes, SCID mice do not mount an inflammatory response against $P$. carinii and do not show signs of respiratory impairment until the advanced stages of disease. Later in the progression of PCP, however, markers of pulmonary inflammation are evident (9-11). To determine when pulmonary function becomes compromised during advanced PCP, arterial oxygen tension and dynamic lung compliance were measured in infected SCID mice at various times after exposure (Figure 1a, Table 3). Again, P. carinii-free SCID mice were used as normal controls for $\mathrm{PaO}_{2}$ and compliance measurements. At 7, 9, and 11 weeks after exposure, the $\mathrm{PaO}_{2}$ values for $P$. carinii-infected SCID mice were within normal parameters at $96 \pm 7.2,97 \pm$ 1.8 , and $101 \pm 2.3 \mathrm{mmHg}$, respectively. Specific dynamic lung compliance was also normal at 9 weeks after exposure $(97 \pm 11 \%)$ when the $P$. carinii burden was 1.68 $\pm 0.53 \times 10^{6} \mathrm{cysts}$ per mouse, confirming that although these mice appeared healthy and demonstrated normal lung function measurements, they harbored significant numbers of organisms. By 12 weeks after exposure, however, the mean $P$. carinii burden was $5.3 \times 10^{6}$ cysts per mouse, and lung function had begun to deteriorate. The mean $\mathrm{PaO}_{2}$ value had dropped to $83 \pm 12$ $\mathrm{mmHg}$, and lung compliance had dropped significantly to $46 \pm 18 \%$ of controls $(P<0.05$, as compared with both $P$. carinii-free SCID mice and $P$. carinii-infected SCID mice at 9 weeks after exposure) (Figure 1a). Further impairment of lung function was detected at 15 weeks after exposure, with the mean lung compliance decreased to $36 \pm 10 \%$ of controls $(P<0.05$ as compared with both $P$. carinii-free SCID mice and $P$. carinii-infect-

Table 3

Time course of pulmonary dysfunction during the progression of PCP in nonreconstituted SCID mice and during the recovery from PCP in immunologically reconstituted SCID mice

\begin{tabular}{|c|c|c|c|c|c|c|c|}
\hline Experimental group & $n$ & $\begin{array}{l}\text { Weeks after } \\
\text { exposure }\end{array}$ & $\begin{array}{l}\text { Immune } \\
\text { reconstitution }\end{array}$ & $\begin{array}{l}\text { Days after } \\
\text { reconstitution }\end{array}$ & $\begin{array}{l}\text { Compliance } \\
\text { (\% of control) }\end{array}$ & $\begin{array}{c}\mathrm{PaO}_{2} \\
(\mathrm{mmHg})\end{array}$ & $\begin{array}{c}\text { Body weight } \\
\text { (g) }\end{array}$ \\
\hline P. carinii-free & 6 & 0 & No & 0 & $100 \pm 21$ & $100.0 \pm 7.3$ & $26.3 \pm 1.4$ \\
\hline P. carinii-free & 5 & 0 & Yes & 12 & $106 \pm 21$ & $100.0 \pm 2.9$ & $25.6 \pm 1.2$ \\
\hline P. carinii-infected & 6 & 7 & No & 0 & ND & $96.0 \pm 7.2$ & ND \\
\hline P. carinii-infected & 6 & 9 & No & 0 & $97 \pm 11$ & $97.0 \pm 1.8$ & $23.1 \pm 1.3$ \\
\hline P. carinii-infected & 6 & 9 & Yes & 12 & $44.0 \pm 8.4^{\mathrm{A}, \mathrm{B}, \mathrm{C}, \mathrm{D}}$ & $71.0 \pm 7.6^{\mathrm{A}, \mathrm{B}, \mathrm{C}, \mathrm{D}, \mathrm{E}}$ & $19.2 \pm 4.0^{\mathrm{A}, \mathrm{B}}$ \\
\hline P. carinii-infected & 5 & 11 & No & 0 & ND & $101.0 \pm 2.3$ & ND \\
\hline P. carinii-infected & 4 & 12 & No & 0 & $46 \pm 18^{\mathrm{A}, \mathrm{C}}$ & $83 \pm 12^{\mathrm{A}, \mathrm{C}, \mathrm{E}}$ & $21.2 \pm 3.0$ \\
\hline P. carinii-infected & 4 & 12 & Yes & 32 & $82 \pm 26$ & $89.0 \pm 7.4$ & $17.9 \pm 1.1^{\mathrm{A}, \mathrm{B}}$ \\
\hline P. carinii-infected & 5 & 15 & No & 0 & $36 \pm 10^{\mathrm{A}, \mathrm{C}}$ & ND & $19.6 \pm 4.9^{\mathrm{A}}$ \\
\hline
\end{tabular}

Pulmonary function measurements were taken in nonreconstituted $P$. carinii-infected SCID mice during the progression of PCP, and in reconstituted $P$. carinii-infected SCID mice during recovery from PCP. Nonreconstituted and reconstituted $P$. carinii-free SCID mice were used as controls. Lung compliance values were corrected for body length and were expressed as percentages of $P$. carinii-free controls. ${ }^{A} P<0.05$ vs. $P$. carinii-free $S C I D$ mice. ${ }^{B} P<0.05$ vs. reconstituted $P$. carinii-free SCID mice. ${ }^{C} P<0.05$ vs. nonreconstituted $P$. carinii-infected SCID mice at 9 weeks after exposure. ${ }^{D} P<0.05$ vs. reconstituted $P$. carinii-infected SCID mice at 32 DAR. E $P<0.05$ vs. nonreconstituted $P$. carinii-infected SCID mice at 11 weeks after exposure. $n$, number of mice in each group. ND, not determined. 


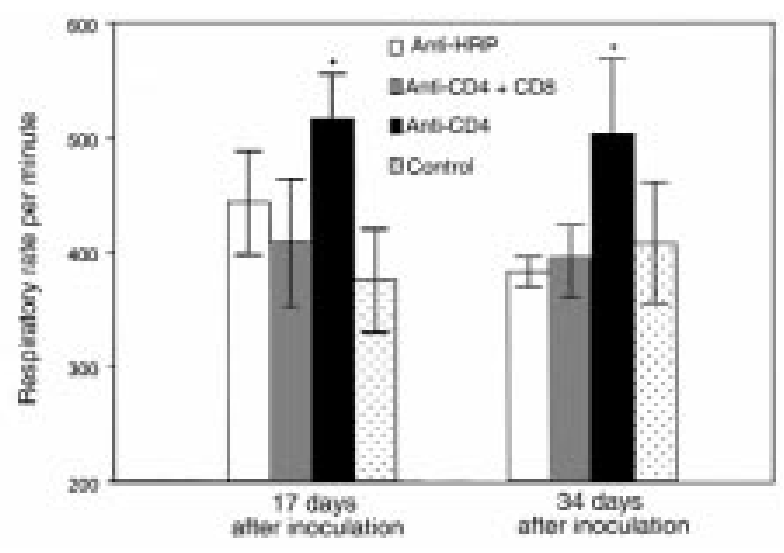

Figure 5

Effect of $C D 8^{+} T$ cells on respiratory rates during PCP in mice. Respiratory rates were measured in CD4-depleted, CD4/CD8-depleted, and anti-HRP-treated mice inoculated with $P$. carinii 17 or 34 days previously. Controls were uninfected C57BL/ 6 mice. Values are mean $\pm 1 \mathrm{SD}(n=5) .{ }^{*} P<0.05$ vs. CD4/CD8-depleted, anti-HRP-treated, and uninfected mice at days 17 and 34 after inoculation.

ed SCID mice at 9 weeks after exposure). The mean $P$. carinii burden in the lungs at this time was $2.2 \times 10^{7}$ cysts per mouse, and differential cell staining demonstrated that of the $2.8 \pm 1.4 \times 10^{6}$ cells recovered in the BALF, $78 \pm 16 \%$ were neutrophils. In the absence of lymphocyte-mediated immunity, $P$. carinii infection reached high numbers in the lungs of SCID mice without adversely affecting pulmonary function. The unchecked progression of PCP, however, eventually led to measurable respiratory impairment, which was associated with neutrophil influx into the lung.

Characterization of the inflammation-associated respiratory impairment following immune reconstitution. When $P$. carinii-infected SCID mice are immunologically reconstituted, an intense inflammatory response was mounted at 10-15 DAR and the infection was cleared over a 21-day period (9). To characterize further the duration and nature of the inflammatory response and related respiratory impairment following reconstitution, organism burdens, $\mathrm{PaO}_{2}$ and lung compliance measurements, and the BALF cell profiles of $P$. carinii-infected SCID mice were determined at various times after reconstitution (Figure 1b, Table 3). At $12 \mathrm{DAR}$ and 9 weeks after exposure to P. carinii, reconstituted SCID mice harbored organism burdens comparable to nonreconstituted littermates at 9 weeks after exposure (1.1 $\pm 0.39 \times 10^{6}$ and $1.68 \pm 0.53 \times 10^{6}$ cysts per mouse, respectively). However, unlike the nonreconstituted mice, the reconstituted SCID mice with PCP displayed intense pulmonary inflammation and impaired pulmonary function. At $12 \mathrm{DAR}$, arterial oxygen tension was significantly decreased to $71 \pm 7.6 \mathrm{mmHg}$, and dynamic lung compliance was decreased to $44 \pm 8.4 \%$ of controls $(P<0.05$, as compared with both $P$. carinii-free control mice and nonreconstituted $P$. carinii-infected SCID mice at 9 weeks after exposure) (Figure 1c, Table 3). Differential staining of BALF obtained at this time demonstrated that of the $1.7 \pm 0.3 \times 10^{7}$ cells recovered, $42 \pm 8.0 \%$ were neutrophils, $42 \pm 11 \%$ were lymphocytes, and $16 \pm 4.0 \%$ were macrophages (Table 4). Furthermore, to ensure that the inflammation-related pulmonary dysfunction was a result of $P$. carinii infection and not a consequence of the reconstitution procedure itself, $P$. carinii-free SCID mice were also reconstituted. At 12 DAR, during the peak inflammatory phase following reconstitution, uninfected SCID mice exhibited normal $\mathrm{PaO}_{2}$ and lung compliance values.

Arterial oxygen tension was also measured in a second group of reconstituted, $P$. carinii-infected SCID mice at $12 \mathrm{DAR}$. As expected, the $\mathrm{PaO}_{2}$ values were significantly decreased during the peak inflammatory stage following reconstitution $(73 \pm 4.5 \mathrm{mmHg})$. Then, at $32 \mathrm{DAR}$, arterial oxygen tension and dynamic lung compliance were measured on these same mice. The reconstituted SCID mice now appeared healthier and exhibited $\mathrm{PaO}_{2}$ and lung compliance values closer to normal. The $\mathrm{PaO}_{2}$ had improved to $89 \pm 7.4 \mathrm{mmHg}$, and lung compliance had improved to $82 \pm 26 \%$ (Figure $1 \mathrm{~b}$, Table 2). The BALF of these mice contained fewer total cells and no detectable neutrophils. Of the $1.0 \pm$ $0.2 \times 10^{6}$ cells recovered, $65 \pm 8.0 \%$ were macrophages and $35 \pm 8.0 \%$ were lymphocytes (Table 4 ). Interestingly, the impairment and restoration of pulmonary function following reconstitution correlated temporally with the onset and resolution of markers of pulmonary inflammation (Figure 2). Thus, the impaired pulmonary function associated with the $P$. carinii-driven inflammatory response in reconstituted, infected SCID mice returns to normal following organism clearance and the resolution of pulmonary inflammation.

$C D 8^{+} T$ lymphocytes exacerbate respiratory impairment during P. carinii pneumonia. To begin to define the cell populations contributing to inflammation-associated

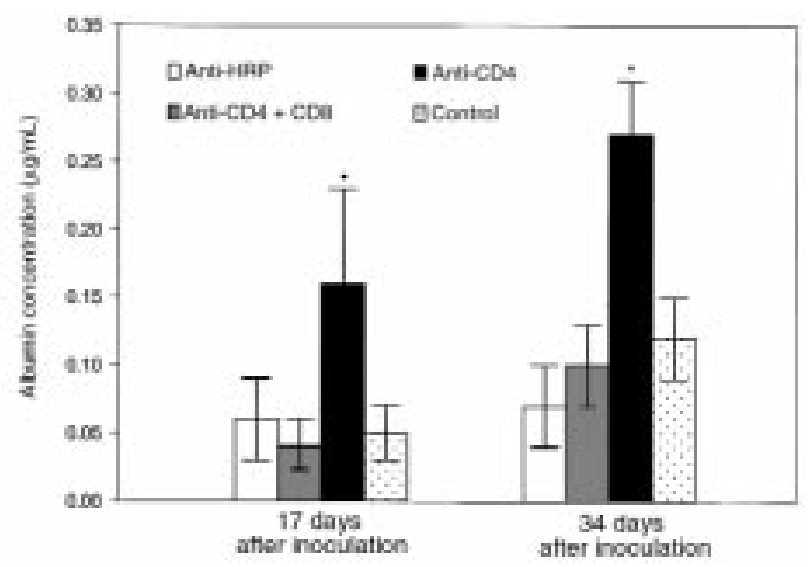

Figure 6

Effect of $C D 8^{+} T$ cells on BALF albumin concentration during PCP in mice. Albumin content was measured in the BALF of CD4-depleted, CD4/CD8-depleted, and anti-HRP-treated mice inoculated with $P$. carinii 17 or 34 days previously. Controls were uninfected C57BL/ 6 mice. Values are mean $\pm 1 \mathrm{SD}(n=5)$. ${ }^{*} P<0.05$ vs. CD4/CD8-depleted, anti-HRP-treated, and uninfected mice at 17 and 34 days after inoculation. 
Table 4

Cellular profiles in the BALF of $P$. carinii-infected SCID mice

\begin{tabular}{|c|c|c|c|c|c|}
\hline Experimental group & $n$ & Total cells & Macrophages (\%) & Neutrophils (\%) & Lymphocytes (\%) \\
\hline $\begin{array}{l}\text { P. carinii-infected, } \\
\text { nonreconstituted, } \\
15 \text { weeks after exposure }\end{array}$ & 5 & $(2.8 \pm 1.4) \times 10^{6}$ & $22 \pm 16 \%$ & $78 \pm 16 \%$ & 0 \\
\hline $\begin{array}{l}\text { P. carinii-infected, } \\
\text { reconstituted, } \\
12 \text { DAR }\end{array}$ & 5 & $(1.70 \pm 0.32) \times 10^{7}$ & $16 \pm 4 \%$ & $42 \pm 8 \%$ & $42 \pm 11 \%$ \\
\hline $\begin{array}{l}\text { P. carinii-infected, } \\
\text { reconstituted, } \\
32 \text { DAR }\end{array}$ & 4 & $(1.0 \pm 0.2) \times 10^{6}$ & $65 \pm 8 \%$ & 0 & $35 \pm 8 \%$ \\
\hline
\end{tabular}

Bronchoalveolar lavage was performed on the experimental groups of $P$. carinii-infected SCID mice that exhibited decreased specific dynamic pulmonary compliance. The total number of cells recovered and the percentage of each cell type, as determined by differential staining, are reported. Values are mean $\pm 1 \mathrm{SD}$, and $n$ is number of mice in each group.

$\mathrm{CD}^{+} \mathrm{T}$ cells exacerbates PCP-associated respiratory impairment in CD4-depleted mice. $C D 8^{+} T$ lymphocytes exacerbate lung injury during $P$. carinii pneumonia. To determine the effect of $\mathrm{CD}^{+} \mathrm{T}$ cells on lung injury during PCP, CD4/CD8-depleted, CD4-depleted, and anti-HRP-treated mice were examined for albumin content in the BALF and LDH levels in the serum (Figures 6 and 7). Despite $P$.

respiratory impairment during $P$. carinii pneumonia, mice depleted of specific T-lymphocyte subsets were studied. Groups of C57BL/6 mice were administered anti-CD4 and anti-CD8 mAbs together, anti-CD4 $\mathrm{mAbs}$ alone, or an isotype-matched control mAb (anti-horseradish peroxidase [HRP]), and then intratracheally inoculated with $10^{7} \mathrm{P}$. carinii nuclei. At 17 and 34 days after inoculation, specific dynamic lung compliance, arterial oxygen tension, and respiratory rates were measured in each experimental group, and also in uninfected control mice. At 17 days after inoculation, the CD4/CD8 depleted mice displayed dynamic lung compliance $\left(1.03 \pm 0.31 \mathrm{~mL} / \mathrm{cmH}_{2} \mathrm{O}\right.$ per kilogram), $\mathrm{PaO}_{2}(97 \pm 3.5 \mathrm{mmHg})$, and respiratory rate (408 $\pm 55 / \mathrm{min})$ measurements that were within normal parameters (Figures 3, 4, and 5). The CD4-depleted mice also exhibited normal compliance (1.30 \pm 0.09 $\mathrm{mL} / \mathrm{cmH}_{2} \mathrm{O}$ per kilogram $)$ and $\mathrm{PaO}_{2}(88 \pm 7.6 \mathrm{mmHg})$ values, but had significantly increased respiratory rates as compared with uninfected controls $(516 \pm 40 / \mathrm{min}$ vs. $375 \pm 45 / \mathrm{min} ; P<0.05)$. As expected, the anti-HRPtreated mice demonstrated normal pulmonary function measurements at 17 days after inoculation.

At 34 days after inoculation (during more advanced $\mathrm{PCP})$, the CD4/CD8-depleted mice maintained normal dynamic lung compliance $\left(1.22 \pm 0.19 \mathrm{~mL} / \mathrm{cmH}_{2} \mathrm{O}\right.$ per kilogram) and respiratory rates $(395 \pm 28 / \mathrm{min})$, but demonstrated decreased $\mathrm{PaO}_{2}$ as compared with uninfected controls $(77 \pm 13 \mathrm{mmHg}$ versus $98 \pm 3.6 \mathrm{mmHg}$; $P<0.05$ ) (Figures 3, 4, and 5). The CD4-depleted mice, however, which had functional $\mathrm{CD}^{+} \mathrm{T}$ cells, demonstrated a much more profound impairment of pulmonary function. Dynamic lung compliance (0.70 \pm $0.14 \mathrm{~mL} / \mathrm{cmH}_{2} \mathrm{O}$ per kilogram) and $\mathrm{PaO}_{2}(66 \pm 13$ $\mathrm{mmHg})$ measurements were dramatically decreased as compared with normal control mice $(P<0.05)$, and respiratory rates remained elevated $(503 \pm 66 / \mathrm{min}$ versus $408 \pm 53 \mathrm{mmHg} ; P<0.05$ ) (Figures 3, 4, and 5). As expected, the anti-HRP-treated mice demonstrated normal pulmonary function measurements at this time. These data demonstrate that the presence of carinii infection, albumin levels in the lungs of CD4/CD8-depleted mice were normal at both 17 and 34 days after inoculation $(0.04 \pm 0.02 \mu \mathrm{g} / \mathrm{mL}$ and 0.10 $\pm 0.03 \mu \mathrm{g} / \mathrm{mL}$, respectively; Figure 6$)$. In contrast, albumin levels in the BALF of CD4-depleted mice (which had functional $\mathrm{CD}^{+} \mathrm{T}$ cells) were significantly elevated to $0.16 \pm 0.07 \mu \mathrm{g} / \mathrm{mL}$ at 17 days after inoculation and to $0.27 \pm 0.04 \mu \mathrm{g} / \mathrm{mL}$ at 34 days after inoculation $(P<0.05$ as compared with uninfected controls). A similar pattern of results was obtained when LDH activity in the sera was measured (Figure 7). Sera from P. carinii inoculated CD4/CD8-depleted mice contained LDH activity equivalent to that of normal, uninfected mice at 34 days after inoculation. LDH activity in the sera of CD4-depleted mice, however, was significantly increased at 34 days after inoculation as compared with uninfected controls and CD4/CD8-depleted mice $(1164+361 \mathrm{BBU} / \mathrm{mL}$ versus $664+202 \mathrm{BBU} / \mathrm{mL} ; P<0.05)$. These data demon-

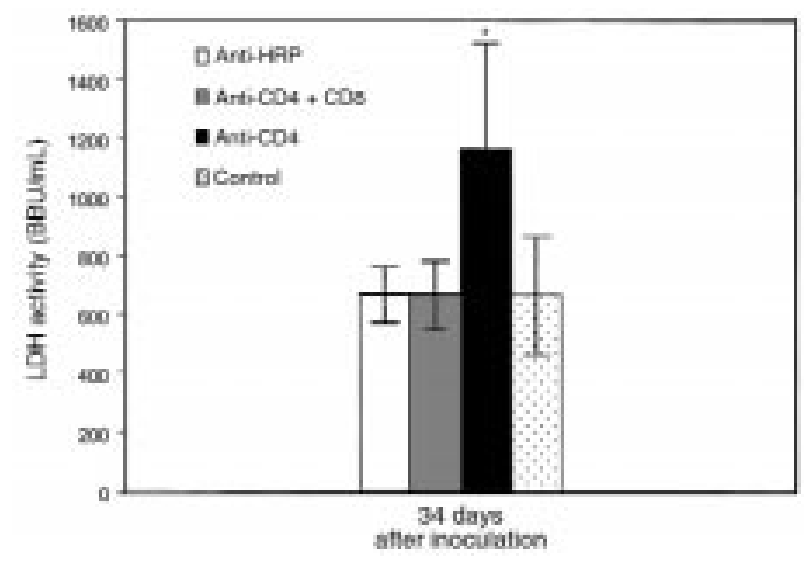

\section{Figure 7}

Effect of $C D 8^{+} T$ cells on serum LDH activity during PCP in mice. $\mathrm{LDH}$ activity in the serum of CD4-depleted, CD4/CD8-depleted, and anti-HRP-treated mice infected with $P$. carinii 34 days previously was measured. Controls were uninfected C57BL/ 6 mice. Values are mean $\pm 1 \mathrm{SD}(n=5) .{ }^{*} P<0.05$ vs. CD4/CD8-depleted, anti-HRP-treated, and uninfected mice at 34 days after inoculation. 


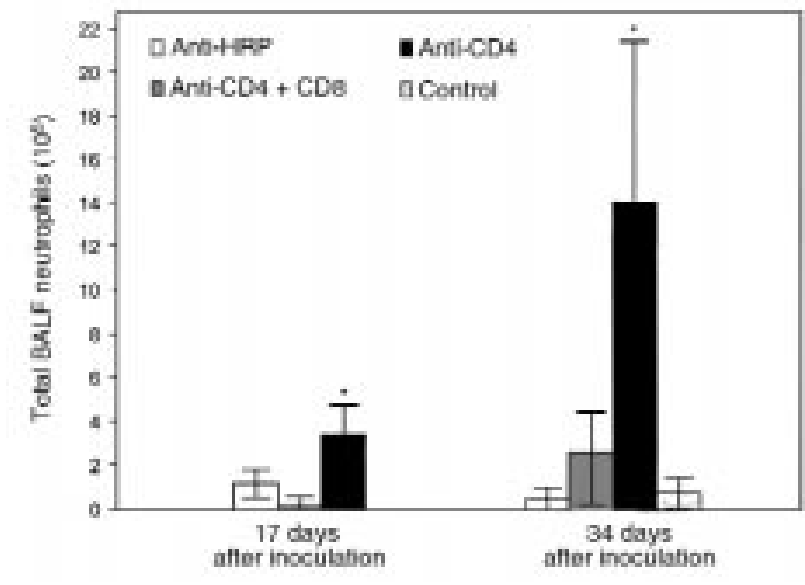

Figure 8

Effect of $C D 8^{+} T$ cells on pulmonary neutrophil recruitment during PCP in mice. Neutrophils were quantified in the BALF of CD4-depleted, CD4/CD8-depleted, and anti-HRP-treated mice infected with $P$. carinii 17 or 34 days previously. Controls were uninfected C57BL/ 6 mice. Values are mean $\pm 1 \mathrm{SD}(n=5)$. ${ }^{*} P<0.05$ vs. CD4/CD8depleted, anti-HRP-treated, and uninfected mice at 17 and 34 days after inoculation.

strate that the presence of $\mathrm{CD} 8^{+} \mathrm{T}$ lymphocytes contributes to pulmonary edema and lung injury during PCP in CD4-depleted mice.

Effect of $C D 8^{+}$T cells on inflammatory cell recruitment and $P$. carinii growth during $P C P$. Histological examination of lung sections from CD4/CD8-depleted and CD4depleted mice yielded results similar to those reported by Beck et al. (19). By 34 days after inoculation, the CD4-depleted mice exhibited a more intense, widespread inflammatory response than CD4/CD8-depleted mice. Pulmonary inflammation in the CD4-depleted mice was characterized by the accumulation of lymphocytic aggregates composed of activated (Lselectin $\left.{ }^{\text {low }}\right) \mathrm{CD}^{+} \mathrm{T}$ cells (data not shown). Differential staining of BALF demonstrated a dramatic increase in neutrophil numbers in the lungs of CD4-depleted mice as compared with CD4/CD8-depleted and uninfected mice at both 17 and 34 days after inoculation (Figure 8). At 17 days after inoculation, CD4-depleted mice had $3.4 \pm 1.4 \times 10^{5}$ BALF neutrophils as compared with only $2.6 \pm 3.2 \times 10^{4}$ neutrophils in the BALF of CD4-depleted mice that were additionally depleted of $\mathrm{CD}^{+}$cells. By 34 days after inoculation, CD4-depleted mice had $1.4 \pm 0.74 \times 10^{6}$ BALF neutrophils as compared with 2.6 $\pm 1.9 \times 10^{5}$ neutrophils in the BALF of CD4/CD8depleted mice. Thus, the presence of $\mathrm{CD}^{+} \mathrm{T}$ cells contributed to increased histological evidence of pulmonary inflammation and increased neutrophil numbers in the BALF of CD4-depleted mice following P. carinii exposure.

Enumeration of P. carinii burdens in the lungs of mice at 17 days after inoculation demonstrated that CD4depleted mice had 3-fold more P. carinii nuclei in the lungs than CD4-depleted mice that were additionally depleted of $\mathrm{CD}^{+}$cells $\left(9.25 \pm 3.48 \times 10^{7}\right.$ vs. $3.08 \pm 1.30$ $\times 10^{7}$ nuclei; $\left.P<0.05\right)($ Table 5$)$. This phenomenon was attributable to an increase in trophozoite numbers in the CD4-depleted mice, because the CD4/CD8-depleted mice actually had 4-fold more cysts than the CD4depleted mice (Table 5). Enumeration of P. carinii at 34 days after inoculation demonstrated that CD4-depleted mice had 10 -fold more $P$. carinii nuclei in the lungs than CD4/CD8-depleted mice $\left(2.80 \pm 1.82 \times 10^{8}\right.$ vs. $2.76 \pm 2.28 \times 10^{7}$ nuclei; $\left.P<0.05\right)$ (Table 5). Again, this difference was attributable to greater trophozoite numbers in CD4-depleted mice, because cyst counts were comparable in both groups (Table 5). As expected, the anti-HRP-treated mice had few $P$. carinii in the lungs and demonstrated normal pulmonary function measurements. Thus, the presence of $\mathrm{CD}^{+} \mathrm{T}$ cells in CD4depleted mice inoculated with $P$. carinii causes an increased accumulation of this organism in the lung.

\section{Discussion}

It is becoming increasingly evident that pulmonary inflammation exacerbates lung injury and contributes to the pathogenesis of many pulmonary diseases (20-23). Studies of the onset and progression of PCP in both human patients and animal models have suggested that the host's ability to mount an inflammatory response correlates directly with the severity of the clinical manifestation of PCP $(6,24)$; however, causal evidence demonstrating that inflammation directly contributes to the pathogenesis of PCP is lacking. Therefore, mouse models of PCP were used to examine the effects of pulmonary inflammation on physiological measurements of lung function during $P$. carinii infection. The SCID mouse provides a well-characterized model of $P$. carinii infection that readily lends itself to experimental manipulation. SCID mice spontaneously develop P. carinii infection, but exhibit neither evidence of pulmonary inflammation nor symptoms of disease until heavy organism burdens are present (9-11). When moderately infected SCID mice are immunologically reconstituted, however, an intense lymphocyte-dependent inflammatory response is mounted against the organism (24). The advantage of this model in terms of these studies is that it allows one to determine the physiologic consequences of infection by $P$. carinii either in the complete absence of an acquired immune response (nonreconstituted mice) or in the presence of a fully functional acquired immune response (reconstituted mice).

Following reconstitution, P. carinii-infected SCID mice demonstrate increased pulmonary cytokine production, focal inflammatory cell recruitment, and resolution of infection over a 21-day period (9-11). To determine the pathophysiological consequences of this inflammatory response, arterial oxygen tension and dynamic lung compliance were measured in nonreconstituted and reconstituted $P$. carinii-infected SCID littermates harboring similar organism burdens. Despite active infection, the nonreconstituted SCID mice appeared healthy and active and demonstrated normal 
oxygenation and lung compliance. In contrast, the reconstituted SCID mice suffered a period of labored breathing and severely impaired pulmonary function, which was followed by clinical improvement as the inflammatory response resolved. A time course of pulmonary inflammation (as represented by TNF- $\alpha$ levels) and pulmonary dysfunction (as represented by specific lung compliance values) following reconstitution of $P$. carinii-infected SCID mice is depicted in Figure 2 (10). These data provide direct experimental evidence that the $P$. carinii-driven inflammatory response contributed to impaired pulmonary function during PCP. Furthermore, in the absence of immune-mediated pulmonary inflammation the organism itself exerted little direct effect on pulmonary function.

Observations made in the reconstituted SCID mouse model of PCP may provide relevant information for the study of PCP in certain patient populations, especially non-AIDS patients. PCP often presents as a more fulminant, acute pulmonary disease in cancer patients and bone marrow transplant patients than in AIDS patients $(2,25)$. For example, among bone marrow transplant patients the clinical onset of PCP coincides with the period of engraftment. Similar to reconstituted SCID mice, these patients may develop subclinical $P$. carinii infections during the period of maximal immunosuppression. Subsequently, restoration of immune (bone marrow) function could result in a $\mathrm{CD}^{+} \mathrm{T}$ cell-mediated inflammatory response against the organism and initiate the clinical onset of PCP. These clinical observations and our results are consistent with the possibility that the clinical signs of PCP are blunted by immunosuppression and that, when present, the inflammatory response to $P$. carinii contributes to lung injury, poor oxygenation, and respiratory impairment. In addition, pulmonary function returns toward normal in mice that survive the inflammatory response following reconstitution. This finding is consistent with data reported by Sanyal et al. examining pulmonary function in children recovered from PCP (26). This report concluded that PCP does not produce chronic pulmonary function deficits in survivors. Thus, this model of PCP allows for the design and evaluation of therapeutic interventions aimed at limiting the injurious effects of the acute $\mathrm{CD}^{+} \mathrm{T}$ cellmediated pulmonary inflammatory response to $P$. carinii.

Despite harboring large numbers of $P$. carinii at 9 weeks after exposure, SCID mice produce little pulmonary inflammation, have normal pulmonary function, and manifest little evidence of PCP. Later in the course of PCP, however, markers of inflammation become evident when large numbers of organism-packed alveoli are found

\section{Table 5}

throughout the lung $(9,10)$. Proinflammatory cytokines are produced and inflammatory cells, including large numbers of neutrophils, are recruited to the lung through a CD4 ${ }^{+} \mathrm{T}$ lymphocyte-independent mechanism. Furthermore, we now have direct evidence that oxygenation and dynamic lung compliance are significantly decreased in SCID mice with advanced PCP. These findings are consistent with data reported by Stokes et al. demonstrating that $P$. carinii-infected, steroid-treated rats have flattened pressure volume curves with advanced PCP, but not with lesser infection (27). Thus, when organism burdens reach a certain threshold, pulmonary inflammation is observed even in the absence of $\mathrm{CD}^{+} \mathrm{T}$ cells. However, this inflammatory response is incapable of resolving $P$. carinii infection and may contribute to neutrophil recruitment, lung injury, and respiratory impairment during PCP.

To better define the contribution of $\mathrm{CD}^{+}$and $\mathrm{CD}^{+}$ cells to the immune-mediated pulmonary injury observed as the host responds to clear $P$. carinii, we employed the $\mathrm{CD}^{+} \mathrm{T}$ cell-depleted mouse model of PCP $(12,13)$. Although the SCID mouse model is ideal for separating the damage caused by the organism directly from the damage resulting from the immune response to $P$. carinii, this model does not lend itself to the study of PCP in patients with chronic, specific $\mathrm{CD}^{+} \mathrm{T}$-cell deficiencies, such as AIDS patients. In the $\mathrm{CD}^{+} \mathrm{T}$ cell-depletion model, once mice are depleted of $\mathrm{CD}^{+} \mathrm{T}$ cells, they become susceptible to infection and develop an ultimately fatal PCP. Thus, this model can be used to examine the role of various cell types on the immunopathogenesis of PCP. We were able to demonstrate that $\mathrm{CD}^{+} \mathrm{T}$ cell-depleted mice developed significant pulmonary compromise over the first 34 days after inoculation with $P$. carinii, showing obvious tachypnea, hypoxia, and decreased dynamic lung compliance at the 34-day time point. In addition, these mice demonstrated a marked influx of activated, Lselectin ${ }^{\text {low }} \mathrm{CD}^{+}$cells and neutrophils into the lung and exhibited classic markers of lung injury and edema. In contrast, when mice were depleted of $\mathrm{CD}^{+}$cells in addition to $\mathrm{CD}^{+}$cells, they had a much milder course after inoculation with $P$. carinii. These mice had only a

P. carinii cyst and trophozoite numbers in the lungs of CD4/CD8-depleted and CD4-depleted mice

\begin{tabular}{lcccc}
\hline Experimental group & $\begin{array}{c}\text { Days after } \\
\text { inoculation }\end{array}$ & $\begin{array}{c}P \text {. carinii } \\
\text { total nuclei } \\
\left(10^{7}\right)^{\mathrm{B}}\end{array}$ & $\begin{array}{c}P \text {. carinii } \\
\text { trophozoites } \\
\left(10^{7}\right)^{\mathrm{B}}\end{array}$ & $\begin{array}{c}\text { P. carinii } \\
\text { cysts } \\
\left(10^{7}\right)^{\mathrm{B}}\end{array}$ \\
CD4/CD8-depleted & 17 & $3.08 \pm 1.30$ & $2.20 \pm 1.20$ & $0.88 \pm 0.49$ \\
CD4-depleted & 17 & $9.25 \pm 3.48^{\mathrm{C}}$ & $9.03 \pm 3.47^{\mathrm{C}}$ & $0.22 \pm 0.09^{\mathrm{C}}$ \\
CD4/CD8-depleted & 34 & $2.76 \pm 2.28$ & $2.17 \pm 1.74$ & $0.59 \pm 0.55$ \\
CD4-depleted & 34 & $28.03 \pm 18.22^{\mathrm{C}}$ & $27.46 \pm 17.78^{\mathrm{C}}$ & $0.57 \pm 0.51$ \\
\hline
\end{tabular}

P. carinii nuclei, cysts, and trophozoites were enumerated in lung homogenates of CD4-depleted and CD4/CD8-depleted mice inoculated with P. carinii 17 or 34 days previously. ${ }^{A}$ Cell depletion began 7 days before challenge with $P$. carinii and continued throughout the experiment. BValues are mean $\pm 1 \mathrm{SD}(n=5)$. ${ }^{c} P<0.05$ vs. CD4/CD8-depleted mice at the same time after inoculation. 
slight decrease in $\mathrm{PaO}_{2}$, whereas lung compliance, serum albumin, and LDH and BALF neutrophil measurements were not statistically different from normal mice that had been inoculated with $P$. carinii but that did not develop PCP. The doubly depleted mice did have a lower organism burden $\left(2.8 \pm 2.3 \times 10^{7}\right.$ total nuclei; $5.9 \pm 5.5 \times 10^{6}$ cysts) compared with the $\mathrm{CD}^{+}$depleted mice $\left(2.8 \pm 1.8 \times 10^{8} ; 5.7 \pm 5.1 \times 10^{6}\right.$ cysts $)$. However, the SCID mice experiments described above indicate that at this moderate burden of $P$. carinii, the inflammatory response to $P$. carinii rather than the $P$. carinii themselves directly causes lung injury. Thus, both the physiologic and morphologic results obtained in these experiments are consistent with the conclusion that $\mathrm{CD}^{+} \mathrm{T}$ cells play a central role in the initiation of the inflammation-mediated pulmonary dysfunction that occurs during PCP in the CD4-deficient host. Our working hypothesis is that in the absence of functional $\mathrm{CD}^{+}$cells, $\mathrm{CD}^{+}$cells trigger a nonproductive inflammatory response that does not result in clearance of organisms, but that may cause bystander injury to the lung through the recruitment of cells and/or cellular products to the lung.

The results presented here are consistent with the findings reported by Beck et al. and Kolls et al., in that the presence of $\mathrm{CD}^{+}$cells exacerbates the pulmonary inflammatory response against $P$. carinii in CD4-depleted mice $(19,28,29)$. Contrary to their findings, however, we demonstrate that $\mathrm{CD}^{+}$cells are not protective against $P$. carinii infection and actually contribute to the immunopathogenesis of PCP. Beck et al. found that $\mathrm{CD}^{+}$cells could account for partial resistance to $P$. carinii (19), whereas Kolls et al. recently showed that $\mathrm{CD}^{+}$cells were effective at clearing $P$. carinii from mice when the mice were also made to overexpress INF- $\gamma$ (29). Experimental design differences likely account for the different results with respect to the ability of $\mathrm{CD}^{+}$ cells to control P. carinii. Beck et al. counted only cyst forms in their study, and we found that the presence of $\mathrm{CD}^{+}$cells had little effect on cyst number, but was associated with a 10 -fold increase in trophozoites. In addition, Beck et al. inoculated fewer organisms $(2 \times$ $10^{5} \mathrm{P}$. carinii cysts vs. $1 \times 10^{7} \mathrm{P}$. carinii nuclei) and sacrificed the mice at an earlier time point after inoculation (4 weeks), indicating that these mice are likely at a lessadvanced stage of infection than the mice in our study. Our early time-point results (17 days) also showed fewer cysts in the presence of $\mathrm{CD}^{+}$cells, but by day 34 the difference had disappeared. Trophozoite numbers were always higher in the presence of $\mathrm{CD}^{+}$cells, however. Therefore, there was much less difference between our results and those of Beck if only cyst numbers are considered at earlier stages of infection.

In summary, we have used a SCID mouse model of PCP to demonstrate that $P$. carinii causes little direct damage to the lung. When SCID mice are immunologically reconstituted, however, the subsequent host response causes significant pulmonary compromise before the infection is resolved. We have also found that in $\mathrm{CD}^{+} \mathrm{T}$ cell-depleted mice, the chronic host inflammatory response to $P$. carinii characterized by the accumulation of large numbers of $\mathrm{CD}^{+}$cells and neutrophils in the lung, causes substantial lung damage. This lung damage is significantly ameliorated when CD4-depleted mice are additionally depleted of $\mathrm{CD}^{+}$ cells, indicating that $\mathrm{CD}^{+}$cells are critical for much of the lung damage observed in CD4-depleted hosts infected with P. carinii. The models developed here can be employed to identify additional cell populations and soluble factors that are responsible for inflammationassociated impairment of pulmonary function during PCP. In addition, novel drug and immune therapies that interfere with the detrimental aspects of the $P$. carinii-driven inflammatory response, while allowing for immune-mediated clearance of the organism from the lung, can be developed and tested.

\section{Acknowledgments}

This work was supported by Public Health Service grant HL-59833-02 from the National Heart, Lung, and Blood Institute, and a grant from the Strong Children's Research Center, Rochester, New York. Pneumocystis carinii pneumonia. Annu. Rev. Med. 45:261-272.

2. Sepkowitz, K.A. 1993. Pneumocystis carinii pneumonia in patients without AIDS. Clin. Inf. Dis. 17(Suppl. 2):S41-S422.

3. CDC. 1989. Guidelines for prophylaxis against Pneumocystis carinii pneumonia for persons infected with Human Immunodeficiency Virus. MMWR Morb. Mortal. Wkly. Rep. 38:(Suppl. 5):1-9.

4. Kovacs, J.A., et al. 1984. Pneumocystis carinii pneumonia: a comparison between patients with the acquired immunodeficiency syndrome and patients with other immunodeficiencies. Ann. Intern. Med. 100:663-671.

5. Benfield, T.L., et al. 1995. Prognostic value of interleukin-8 in AIDS-associated Pneumocystis carinii pneumonia. Am. J. Respir. Crit. Care Med. 151:1058-1062.

6. Limper, A.H., Offord, K.P., Smith, T.F., and Martin, W.J., II. 1989. Pnenmocystis carinii pneumonia: differences in lung parasite number and inflammation in patients with and without AIDS. Am. Rev. Respir. Dis. 140:1204-1209.

7. The National Institutes of Health-University of California Expert Panel for Corticosteroids as Adjunctive Therapy for Pneumocystis Pneumonia. 1990. Consensus statement on the use of corticosteroids as adjunctive therapy for Pneumocystis pneumonia in the Acquired Immunodeficiency Syndrome. N. Engl. J. Med. 323:1500-1504.

8. Roths, J.B., Marshall, J.D., Allen, R.D., Carlson, G.A., and Sidman, C.L. 1990. Spontaneous Pneumocystis carinii pneumonia in immunodeficient mutant scid mice. Am. J. Pathol. 136:1173-1186.

9. Chen, W., Mills, J.W., and Harmsen, A.G. 1992. Development and resolution of Pneumocystis carinii pneumonia in severe combined immunodeficient mice: a morphological study of host inflammatory responses. Int. J. Exp. Pathol. 73:709-720.

10. Wright, T.W., Johnston, C.J., Harmsen, A.G., and Finkelstein, J.N. 1997. Analysis of cytokine mRNA profiles in the lungs of Pneumocystis cariniiinfected mice. Am. J. Respir. Cell Mol. Biol. 17:491-500.

11. Wright, T.W., Johnston, C.J., Harmsen, A.G., and Finkelstein, J.N. 1999. Chemokine gene expression during Pneumocystis carinii-driven pulmonary inflammation. Infect. Immun. 67:3452-3460.

12. Harmsen, A.G., and Stankiewicz, M. 1990. Requirement for $\mathrm{CD}^{+}$cells in resistance to Pneumocystis carinii pneumonia in mice. J. Exp. Med. 172:937-945.

13. Shellito, J., et al. 1990. A new model of Pneumocystis carinii infection in mice selectively depleted of helper $\mathrm{T}$ lymphocytes. J. Clin. Invest. 85:1686-1693.

14. Chen, W., Gigliotti, F., and Harmsen, A.G. 1993. Latency is not an inevitable outcome of infection with Pneumocystis carinii. Infect. Immun. 61:5406-5409.

15. Harmsen, A.G. 1988. Role of alveolar macrophages in lipopolysaccharide-induced neutrophil accumulation. Infect. Immun. 56:1858-1863.

16. Bergmann, K.C., Lachmann, B., and Noack, K. 1984. Lung mechanics in orally immunized mice after aerosolized exposure to influenza virus. Respiration. 46:218-221. 
17. Amdur, M.O., and Mead, J. 1958. Mechanics of respiration in unanesthetized guinea pigs. Am. J. Physiol. 192:364-368.

18. Wiley, J.A., Geha, R., and Harmsen, A.G. 1997. Exogenous CD40 ligand induces a pulmonary inflammation response. J. Immunol. 158:2932-2938.

19. Beck, J.M., et al. 1996. Role of CD8 ${ }^{+}$lymphocytes in host defense against Pneumocystis carinii in mice. J. Lab. Clin. Med. 128:477-487.

20. Shanley, T.P., Warner, R.L., and Ward, P.A. 1995. The role of cytokines and adhesion molecules in the development of inflammatory injury. Mol. Med. Today. 1:40-45.

21. Agostini, C., and Semenzato, G. 1996. Immunology of idiopathic pulmonary fibrosis. Curr. Opin. Pulm. Med. 2:364-369.

22. Driscoll, K.E., Carter, J.M., Hassenbein, D.G., and Howard, B. 1997. Cytokines and particle-induced inflammatory cell recruitment. Environ. Health Perspect. 105(Suppl. 5):1159-1164.

23. Ward, P.A., and Hunninghake, G.W. 1998. Lung inflammation and fibrosis. Am. J. Respir. Crit. Care Med. 157:S123-S129.
24. Roths, J.B., and Sidman, C.L. 1992. Both immunity and hyperresponsiveness to Pneumocystis carinii result from transfer of $\mathrm{CD}^{+}$but not $\mathrm{CD}^{+} \mathrm{T}$ cells into severe combined immunodeficiency mice. J. Clin. Invest. 90:673-678.

25. Varthalitis, I., and Meunier, F. 1993. Pneumocystis carinii pneumonia in cancer patients. Cancer Treat. Rev. 19:387-413.

26. Sanyal, S.K., et al. 1981. Course of pulmonary dysfunction in children surviving Pneumocystis carinii pneumonitis. Am. Rev. Respir. Dis. 124:161-166.

27. Stokes, D.C., et al. 1986. Lung mechanics, radiography and ${ }^{67} \mathrm{Ga}$ scintigraphy in experimental Pneumocystis carinii pneumonia. Br. J. Exp. Pathol. 67:383-393

28. Beck, J.M., et al. 1991. Inflammatory responses to Pneumocystis carinii in mice selectively depleted of helper T lymphocytes. Am. J. Respir. Cell Mol. Biol. 5:186-197.

29. Kolls, J.K., et al. 1999. IFN- $\gamma$ and $\mathrm{CD}^{+} \mathrm{T}$ cells restore host defenses against Pneumocystis carinii in mice depleted of CD $4^{+} \mathrm{T}$ cells. J. Immunol. 162:2890-2894. 